Archives

$21 \mid 1998$

1. Pour une histoire comparée du voeu // 2. Les

Cagots

\title{
Du vœu royal au vœu national
}

Une histoire du XIX ${ }^{\mathrm{e}}$ siècle

Miguel Rodriguez

\section{(2) OpenEdition}

Journals

Édition électronique

URL : http://journals.openedition.org/ccrh/2513

DOI : $10.4000 /$ ccrh.2513

ISSN : $1760-7906$

Éditeur

Centre de recherches historiques - EHESS

Édition imprimée

Date de publication : 1 novembre 1998

ISSN : 0990-9141

Référence électronique

Miquel Rodriguez, «Du vœu royal au vœu national », Les Cahiers du Centre de Recherches Historiques

[En ligne], 21 | 1998, mis en ligne le 20 avril 2009, consulté le 19 avril 2019. URL : http://

journals.openedition.org/ccrh/2513; DOI : 10.4000/ccrh.2513

Ce document a été généré automatiquement le 19 avril 2019.

Article L.111-1 du Code de la propriété intellectuelle. 


\title{
Du vœu royal au vœu national
}

\author{
Une histoire du XIX ${ }^{\mathrm{e}}$ siècle
}

Miguel Rodriguez

1 Dans la dévotion au Sacré Cœur, le concept de vœu est fondamental, en tant que " promesse faite à Dieu ». De la relation spirituelle des mystiques avec Dieu au « vœu national », en passant par la fondation d'ordres se réclamant du Sacré Cœur, l'histoire de la dévotion montre que le vœu assumé, vis-à-vis de cette figure, peut être, aussi bien un comportement individuel qu'une manifestation de foi collective: il va associer au XIX siècle un engagement religieux et des pratiques laïques. Le vœu au Sacré Cœur semble correspondre au cadre définitionnel proposé pour le projet d'une histoire comparée du vœu :

[...] une norme surérogatoire par rapport aux normes communes, qui entend former une excellence des individus ou des groupes limités et qui se noue devant une instance transcendante, divine ou éthique ${ }^{1}$.

2 La dévotion au Sacré Cœur, qui existe au Moyen Âge sous la forme des cinq plaies du Christ, atteint son épanouissement avec Jean Eudes, puis avec Marguerite-Marie d'Alacoque, dans la seconde moitié du XVII ${ }^{\mathrm{e}}$ siècle : c'est avec elle que la symbolique du culte prend ses traits durables - presque jusqu'à nos jours - et, c'est sous cette forme qu'elle atteint les horizons les plus vastes. Ainsi il sera question ici du Sacré Cœur dans le sens qui lui a été donné à partir de Paray-le-Monial, où vécut Marguerite-Marie d'Alacoque.

3 La sainte rapporte de nombreuses visions surnaturelles entre 1673 et sa mort, en 1690 : il s'agit d'un échange constant avec Jésus-Christ qui se montre devant la religieuse avec ses cinq plaies, en découvrant son cœur :

[...] voilà ce cœur qui a tant aimé les hommes...

Lors de ces apparitions, selon les écrits de Marguerite-Marie d'Alacoque, le Christ réclame les pratiques qui vont constituer la dévotion au Sacré Cœur.

5 Parmi ces demandes on ne traitera ici que celles qui sollicitent une dévotion collective, une reconnaissance publique: c'est le sens de ce qui a été appelé le message pour 
Louis XIV. Il semblerait que la sainte en prenne connaissance à la fin de sa vie, en 1689, le vendredi après l'octave du Saint-Sacrement, si l'on en croit la lettre qu'elle écrit à la mère de Saumaise - celle qui fut sa première supérieure :

[...] ce divin cœur désire donc, ce me semble, entrer avec pompe et magnificence dans la maison des princes et des rois, pour y être honoré autant qu'il y a été outragé, méprisé et humilié en sa Passion et pour qu'il reçoive autant de plaisir de voir les grands de la terre abaissés et humiliés devant lui, comme il a senti l'amertume de se voir anéanti à leurs pieds. Et voici les paroles que j'entendis sur ce sujet: " Fais savoir au fils aîné de mon sacré Cœur-parlant de notre roi-que, comme sa naissance temporelle a été obtenue par la dévotion aux mérites de ma sainte Enfance, de même il obtiendra sa naissance de grâce et de gloire éternelle par la consécration qu'il fera de lui-même à mon Cœur adorable, qui veut triompher du sien, et par son entremise de celui des grands de la terre. Il veut régner dans son palais, être peint dans ses étendards et gravé dans ses armes, pour les rendre victorieuses de tous ses ennemis, en abattant à ses pieds ces têtes orgueilleuses et superbes, pour le rendre triomphant de tous les ennemis de la sainte Église $»^{2}$.

En août 1689, une autre lettre rapporte une nouvelle révélation qui vient compléter la demande au Prince :

[...] le Père éternel voulant réparer les amertumes et angoisses que l'adorable cœur de son divin Fils a reçues dans la maison des princes de la terre, parmi les humiliations et les outrages de sa Passion, veut établir son empire dans le cœur de notre grand monarque, duquel il veut se servir pour l'exécution de ce dessein qu'il désire pour voir s'accomplir en cette manière, qui est de faire faire un édifice où serait le tableau de ce divin cœur pour y recevoir la cour et les hommages $[. . .]^{3}$.

\section{Un antécédent, le vœu de louis XIII}

7 En 1638, pendant les guerres franco-espagnoles, Louis XIII fait le vœu de placer, dans la cathédrale de Paris, une image de la Vierge Marie qui tienne dans ses bras son fils descendu de la Croix. Voilà sans doute l'origine du célèbre tableau de Philippe de Champaigne, où l'on voit, agenouillé devant cette mater dolorosa, le Roi orné des insignes royaux, faisant don de sa couronne et de son sceptre à la Vierge :

$[. .$.$] «nous avons déclaré et nous déclarons que prenant la Très-Sainte et la Très-$ Glorieuse Vierge pour Patronne spéciale de notre royaume, nous lui consacrons particulièrement notre Personne, notre Couronne et nos sujets, la suppliant de nous vouloir inspirer une sainte conduite et défendre avec tant de soin ce royaume contre l'effort de tous ses ennemis que, soit s'il souffre le fléau de la guerre ou jouisse de la douceur de la paix, nous demandons à Dieu de tout cœur qu'il ne sorte pas des voies de la grâce qui conduisent à celles de la gloire $»^{4}$.

8 Le vœu, rendu public en février 1638, est renouvelé par une procession à Notre-Dame de Paris le 15 août de cette même année, quelques jours seulement avant la naissance du dauphin, si longtemps attendu: la littérature qui traite de ce fait insiste sur l'interdépendance entre la continuité de la monarchie et la publication du voeu, dont le caractère institutionnel transparaît clairement dans le tableau officiel de Philippe de Champaigne. Ce n'est pas seulement sa personne ni sa famille que le roi veut placer sous la protection de la divinité par l'intermédiaire d'une image et une pratique rituelle, mais le royaume tout entier ${ }^{5}$. 


\section{Le vœu de louis XIV}

9 Il en va tout autrement de l'engagement du successeur de Louis XIII. Il n'est plus question de la figure mariale mais de celle, christologique, du Sacré Cœur dont Marguerite-Marie d'Alacoque veut être la propagatrice. Cette nouvelle dévotion, qui se développe pendant le $\mathrm{xVIII}^{\mathrm{e}}$ siècle, est alors d'ordre intime. Elle est fondée sur une pratique spirituelle individuelle qui n'engage, à la limite, que la collectivité organisée dans une congrégation religieuse. Le jésuite Jean Croiset, qui publie au lendemain de la mort de MargueriteMarie une première biographie fréquemment rééditée et traduite tout le long du XVIII ${ }^{\mathrm{e}}$, ne souffle mot du message adressé à Louis XIV. Il n'en est rien, non plus, dans la célèbre histoire de Jean-Joseph Languet qui a connu les écrits originaux et les témoignages des contemporaines de la sainte à Paray-le-Monial, publiée pour la première fois en 1729.

Enfin, le classique ${ }^{6}$ de Joseph de Galliffet, Excellence de la dévotion au cour adorable de JésusChrist, publié en latin en 1726, demande instamment la concession d'une fête particulière à la nouvelle dévotion, d'un office et une messe propre aux royaumes d'Espagne que Philippe $\mathrm{V}$ avait demandés comme un privilège au pape Benoît XIII. Mais dans ce texte il n'est pas question d'une communication d'ordre surnaturel entre Dieu et le Prince, dans la perspective d'un vœu collectif d'un peuple. En citant des extraits de quelques lettres de Marguerite-Marie d'Alacoque, Galliffet parle plutôt d'un

[...] projet d'un vœu de perfection hérö̈que formé et exécuté par la Vénérable Mère, pour s'unir plus étroitement au Sacré Cœur et s'engager à répondre à ses révélations :

[...] m'engager indispensablement à ce qu'il me fait connaître désirer de moi.

Par ailleurs, Galliffet montre que nombreux sont ceux qui ne croient pas à ces révélations puisque l'un des premiers chapitres de son ouvrage veut prouver leur caractère véridique.

11 Les révélations de 1689 et l'appel au roi ne seront connus publiquement que lors de la publication, en 1867, des écrits de Marguerite-Marie d'Alacoque, dans la foulée de sa béatification qui a lieu en 1864. Au milieu du XIX la dévotion vit son plein épanouissement: un moyen important de diffusion de la dévotion, qui n'en est pas le seul - loin s'en faut -, est le Messager du Sacré Cœur de Jésus, publié dès les années soixante en langues différentes dans de nombreux pays. L'édition française d'août 1867 annonce des écrits de la sainte, jusqu'alors inconnus :

[...] ces lettres contiennent le récit de plusieurs révélations encore inédites, par lesquelles Notre Seigneur a fait connaître à sa servante ses desseins relativement à la dévotion à son divin cœur. Quelques unes de ces révélations regardent spécialement la France et le roi Louis XIV auquel le Père de la Chaise était chargé de faire connaître cette dévotion et de promettre au nom de Notre Seigneur d'abondantes bénédictions, s'il consentait à user de son influence pour faire honorer le cœur de Jésus $»^{7}$.

12 Mais pourquoi ce message n'a-t-il pas été connu plus tôt? Une abondante discussion nourrira pendant des décennies la littérature de dévotion, étonnée d'une découverte aussi tardive. En particulier, le jésuite Auguste Hamon, qui consacre sa vie à une monumentale histoire de la dévotion en cinq volumes, publie, en 1918, une étude historique et critique sur les avatars du message ${ }^{8}$ : il soutient que Languet l'aurait connu parmi les documents recueillis chez les visitandines de Paray-le-Monial, puisque dans l'édition de son livre en 1729 , il fait des allusions voilées à ce message ; mais, qu'il l'aurait supprimé 
explicitement de sa Vie de Marguerite-Marie d'Alacoque à cause des attaques jansénistes dont il aurait pu être l'objet.

13 Si Languet a pu connaître ces passages il n'en reste plus de traces parmi les documents autographes conservés dans les monastères de la Visitation. Les spécialistes les plus récents de Marguerite-Marie d'Alacoque mettent en garde au sujet du maniement des sources : écrits autobiographiques en plusieurs copies, doublets souvent différents et mal datés, qu'il faudrait contrôler et mettre au point... ${ }^{9}$ 'édition donnée en 1867 par Gauthey - qui reprend en grande partie le texte de Languet, tout en y ajoutant des documents inédits-, considérée comme la source fondamentale pour connaître la spiritualité de la bienheureuse, ne donne pas une explication convaincante au sujet de la transmission du message.

On est donc tenté de voir dans ces documents restés inédits jusqu'en 1867 un message dont la fonction politique ne peut être comprise qu'à la lumière $d u x^{2} x^{e}$ siècle. Ce qui n'empêche pas Jacques Le Brun ${ }^{10}$ d'expliquer l'appel au «fils aîné » du Sacré Cœur dans le contexte d'inquiétude qui a suivi la Révolution d'Angleterre et les menaces de la Ligue d'Augsbourg contre la France catholique, tandis que les Turcs constituent toujours un danger aux portes de l'Europe.

Quoi qu'il en soit et, indépendamment de sa publication, pourquoi le message à Louis XIV n'a-t-il pas été transmis à son destinataire ? Certains essaient de saisir comment - ce qui semble impossible-cette démarche divine n'a pas pu atteindre son but. D'autres expliquent qu'à travers le souverain c'est à la France que Dieu s'adresse. Et, tout en reconnaissant les péchés du roi, ils signalent que ce sont les fautes de la nation qu'il faudra réparer. Dans les deux corps du roi, se manifesteront, la gravité de la faute, mais aussi la nécessaire expiation : dans cette dimension réparatrice qui, depuis Alacoque, est caractéristique de la dévotion au Sacré Cœur.

Parmi de nombreux auteurs qui s'interrogent sur les raisons du silence de Louis XIV au sujet du vœu, le chanoine Cucherat, dans un livre sur les pèlerinages à Paray-le-Monial, daté de 1873, rend compte de l'état de l'opinion aux lendemains de la publication du message :

Marguerite-Marie d'Alacoque a rempli sa mission. Le Sacré Cœur lui a dit de parler ; il ne l'a pas rendue responsable du non-succès. On n'a plus entendu parler de la chose. On ignore si la défaillance est venue des religieux, du père de La Chaise ou du roi. Mais il est arrivé, cette fois encore, comme au temps de Noë. Le Sacré Cœur était l'arche nouvelle. Cent ans ont été donnés comme autrefois au monde pour se convertir. Le monde ne l'a pas voulu et l'infidelité et l'ingratitude n'ont fait que le rendre de plus en plus coupable....11

Aux lendemains du désastre de 1870, il compare celui-ci au déluge, et la tour de Babel à l'impiété et aux désordres de l'époque moderne. Pour lui, comme pour beaucoup d'autres dans le climat de détresse de cette décennie, une seule réparation possible: se réfugier dans le Sacré Cœur. Il est urgent de rétablir un contrat entre le Sacré Cœur et la patrie. Ne pas l'avoir honoré en 1689 est à l'origine des malheurs qui cent ans après vont se déclencher en France et, par sa faute, dans le monde entier. On ira jusqu'à associer la date de la révélation du message au roi en 1689 - la fête du Sacré-Cœur, le 17 juin - avec la transformation du tiers état en Assemblée nationale, qui a lieu, jour pour jour, un siècle plus tard. 


\section{Le vœu de louis XVI}

17 Evidemment, tenir la Révolution pour coupable de tous les maux du monde moderne n'est pas nouveau. Dès les premières années de la Restauration, il est courant d'entendre que Le Salut de la France repose sur la dévotion au cœur blessé surmonté d'une croix - couverture d'un ouvrage anonyme de 1818, attribué au père jésuite Ronsin.

C'est peut-être pour avoir combattu cette dévotion, ou ne l'avoir pas assez soutenue, que nous avons vu l'irréligion faire tant de progrès parmi nous et les ennemis de la foi divine assez puissants pour renverser les temples et les autels ${ }^{12}$.

Le Salut de la France inclut un texte qui commence à circuler pendant ces années de Restauration, connu comme «le vœu de Louis XVI » : le supérieur général des eudistes, Monsieur Hébert, l'aurait reçu, en tant que confesseur du roi, emprisonné au Temple en 1792. Dans ce texte, coupable de ses fautes, Louis XVI aurait promis solennellement, s'il retrouvait sa liberté, sa couronne et sa puissance royales, de révoquer toutes les lois qui lui seraient indiquées, soit par le pape, soit par un concile, en particulier la Constitution civile du clergé ; il s'engageait aussi à établir une fête solennelle en l'honneur du Sacré Cœur; à aller à Notre Dame pour y prononcer un acte solennel de consécration de sa personne, de sa famille et de son royaume au Sacré Cœur, acte qui serait renouvelé tous les ans ; enfin, à ériger une chapelle ou un autel,

$\left[\right.$ [...] un monument éternel de reconnaissance et de confiance sans bornes ${ }^{13}$.

Ces promesses à la divinité concernent non seulement des aspects de la pratique dévotionnelle qui se sont développés pendant le $\mathrm{xvIII}{ }^{\mathrm{e}}$ siècle - instauration de la fête, construction de lieux de culte - mais aussi les exigences politiques de la Restauration quant au rétablissement des droits du clergé. Pendant ces années il est question de reconnaître le roi guillotiné comme martyr, en vue d'une cause de béatification qui sera étudiée, sans succès, par Rome ${ }^{14}$. Le vœu de Louis XVI fut ajouté aussitôt à l'histoire de la dévotion, apparaissant déjà dans l'édition de 1832 de l'ouvrage de Galliffet. L'engagement royal en 1792 étant par les circonstances, secret, une partie du vœu consiste à le rendre public le jour («le plus beau jour de ma vie» dit le vœu du roi guillotiné) où il serait exprimé à haute voix dans le temple. Vœu inaccompli à deux reprises, toutes les deux associées à la catastrophe révolutionnaire; la consécration au Sacré Cœur apparaît aux catholiques de la première moitié du XIX ${ }^{e}$ siècle, légitimistes pour la plupart, comme la seule issue aux malheurs de la France dont le plus grand est le régicide.

Dans les années 1860, lorsque «le vœu de Louis XIV» est connu, la littérature dévotionnelle insiste sur la continuité du rapport que la divinité veut établir avec la France à travers le monarque. On trouvera des analogies entre les demandes à l'un et les promesses de l'autre: mais Louis XVI peut-il connaitre le message adressé à son prédécesseur? Le père Hamon, le grand historien de la dévotion, tente de contourner les difficultés :

[...] on objectera que, peut-être, il n'y pense pas, alors il faut dire que les choses se passent comme s'il y pensait, et le Cœur Sacré de Jésus, en acceptant le vœu, y pense certainement ${ }^{15}$.

Parmi bien d'autres, le jésuite Victor Alet ouvre son livre sur La France et le Sacré Cour par un rapprochement entre «les trois 89 »: puisqu'en 1689 la consécration de la France demandée à Marguerite-Marie d'Alacoque n'a pas eu d'écho chez un roi sourd, puisque la consécration que la Révolution de 1789 a suscité chez un roi déchu ne pouvait pas être 
solennelle et publique, en 1889-l'année du Centenaire et aussi de la publication du livre - la France pécheresse se doit de réparer ses fautes, le pays infidèle de rétablir le contrat établi avec la divinité. Et, par l'accomplissement du vœu, la France oblige le Sacré Cœur à reverser sur elle les grâces qui lui ont été promises. Face à la tour Eiffel, sur le ciel et au-dessus des toits gris de la capitale, va s'élever le dôme blanc du Sacré-Cœur. La proclamation des «droits de Dieu » veut effacer la célébration centenaire des droits de l'homme. Le vœu royal devient le vœu national.

\section{Ex-voto au cœur de la nation}

Les brochures ou opuscules qui traitent du vœu au Sacré Cœur, durant ces années autour de la béatification de Marguerite-Marie d'Alacoque, montrent comment se forge le sens du vœu national. En 1863, un voeu de consécration aux Sacrés Coeurs de Jésus et de Marie ${ }^{16}$. est encore envisagé dans une dimension toute personnelle, comme un vœu pleinement religieux :

$[. .$.$] je voue et je consacre à ce divin cœur tout ce que j'ai et tout ce que je suis.$

Celui qui le prononce s'engage à renouveler la consécration au Sacré Cœur par le respect des fêtes et des pratiques qui lui sont spécifiques - la communion, les premiers vendredis du mois - ainsi qu'à étendre la dévotion parmi d'autres fidèles.

Dès les premières défaites de la guerre franco-prussienne, dès la chute de l'Empire et l'entrée des troupes italiennes dans Rome, se fait jour l'idée dans de nombreux écrits d'une consécration collective,

[...] sorte d'expiation de fautes nationales ou le dur aiguillon pour un relèvement nécessaire ${ }^{17}$.

Le prêche du jésuite Marin de Boylesve au Mans, l'anniversaire de la mort de MargueriteMarie d'Alacoque, le 17łoctobre 1870, est diffusé en feuille volante à plus de 300000 exemplaires, ensuite par le Messager : la France doit retrouver son rôle de nation la plus chrétienne en faisant amende honorable et en se consacrant au Sacré Cœur, dans la lignée du vœu royal ; plus tard, dans son livre de 1884, La France et le Cœur de Jésus, cet auteur mettra en opposition le mot "Révolution» et «tous les titres de la France à la miséricorde » allant de Clovis et Charlemagne aux zouaves pontificaux, en passant par le vœu de Louis XIII et celui de Louis XVI ${ }^{18}$.

En 1871 on fait circuler un vœu au Sacré Coeur pour la délivrance du Souverain Pontife et celle de la France, au ton culpabilisateur, avec de fortes résonances autant hostiles au protestantisme qu'à l'Allemagne. Le «vœu de Poitiers»-l'engagement de certains catholiques afin de construire un temple votif - exprime le passage de la collectivité, du « nous ", à la nation :

Nous voulons former un immense faisceau de volontés protestataires de leur soumission au Seigneur, reconnaissant sa main dans nos malheurs, s'humiliant pour obtenir son appui et faisant ainsi une amende honorable nationale pour nos crimes nationaux ${ }^{19}$.

Contrairement à l'opinion courante qui voit dans l'église construite à Montmartre une réponse de la droite bourgeoise à la Commune, l'idée de construire un monument d'expiation nationale est antérieur au soulèvement révolutionnaire. La construction d'un lieu de culte matérialise la nouvelle alliance entre la divinité et la nation : c'est un ex-voto monumental que la France toute entière va réaliser, par le soutien officiel des représentants du peuple, ainsi que par les contributions économiques, les prières et la 
visite en pèlerinage de chaque fidèle. Dans le Bulletin de l'Euvre du voeu national, fréquemment, on compare la basilique en construction à

[...] une reproduction de l'arche de l'alliance qui servait comme un signe, un symbole, au peuple de Dieu, qui lui rappela les engagements pris avec de tous les temps avec le Dieu d'Abraham, d'Isaac et de Jacob. Toutes les prières, tous les sacrifices, toutes les invocations seront dirigées vers le lieu où repose l'arche de l'alliance, devenu le centre, le foyer de la vie religieuse de la nation élue ${ }^{20}$.

Si la Basilique du vœu national met de longues années avant de sortir de terre - sa silhouette actuelle date de 1890 mais l'inauguration complète a lieu en 1919-, les concepteurs du projet tiennent à ce que le chantier devienne rapidement un lieu de pèlerinage: les visiteurs contribuent avec leur affluence et leurs dons à continuer l'œuvre. Ce n'est pas le seul monument où l'on rend hommage au Sacré Cœur pour la «résurrection» de la France; Paray-le-Monial devient, dans les années qui suivent la défaite de 1870 , le but d'importantes manifestations à caractère patriotique - ce qui n'empêche pas la venue de nombreux visiteurs étrangers. Michel Cinquin, qui s'est penché sur ces pèlerinages à la ville de Marguerite-Marie d'Alacoque, conclut :

On ne vient pas à Paray pour guérir des maladies physiques; au niveau national il y

a Lourdes. À Paray on soigne les âmes inquiètes et les nations malades; on prie pour la régénération religieuse et morale de la Patrie...21. Ainsi en juin 1873, 200 députés souscrivent à un hommage au Sacré Cœur - même si seulement une cinquantaine parmi eux fait le voyage à la ville bourguignonne. Ce pèlerinage, où le baron Gabriel de Belcastel lit un texte d'allégeance au nom de ses collègues, matérialise l'association du symbole religieux et d'une entité politique - la représentation nationale. Pour le père Drevon, organisateur de ce grand pèlerinage de 1873,

Paray constitue le cœur de la France, un foyer de régénération surnaturelle, comme une source de grâces et de vie ${ }^{22}$.

Le tournant des années 1870 voit foisonner des prodiges et des miracles, des prédictions et des prophéties : la diffusion et l'emprise du vœu national se comprend aisément dans cet essor du sentiment religieux - dans le sens le plus large du terme.

Quelques années plus tard, les concentrations de 1889 à Paray-le-Monial contrebalancent la célébration républicaine du centenaire de la Révolution et préparent le bicentenaire de la mort de la bienheureuse : c'est «la belle époque des pèlerinages " ${ }^{23}$. Mais Paray ne constitue cependant pas le foyer du vœu national autant que ne l'est déjà la grande basilique en construction à Paris.

Le message à Louis XIV, ignoré jusque en 1867, lui demande aussi de peindre le Sacré Cœur dans ses étendards. Il en aurait déjà été question dans une lettre de la supérieure de Paray-le-Monial à Languet en 1744 : il y était prédit que les armées françaises seraient victorieuses si la représentation du Sacré Cœur de Jésus était arborée sur leurs drapeaux. Mais cette lettre autographe, dont la conservation, aux dires du père Hamon, est un "petit miracle ${ }^{24}$ n'est connue que depuis 1891 . Or c'est précisément en 1890 que l'on a les premières traces de drapeaux du Sacré Cœur à Montmartre, portés par le syndicat des employés du commerce et de l'industrie ${ }^{25}$ : des drapeaux tricolores avec le cœur du Christ entouré d'épines et surmonté d'une croix au milieu du blanc, «trois couleurs ainsi embellies et comme surnaturalisées ${ }^{26}$. Le drapeau tricolore rejeté par le comte de Chambord-refus qui empêche la solution légitimiste et ouvre la voie à la $\mathrm{III}^{\mathrm{e}}$ République - est alors enfin reconnu par la droite catholique, à une époque où les 
socialistes et les syndicalistes - fidèles au rouge - rejettent à leur tour le drapeau tricolore comme symbole de la république bourgeoise.

Pendant la guerre de 1914, lorsque la dévotion est touchée par le sentiment patriotique, le "drapeau du Sacré Cour», censé pouvoir sauver la France et la rendre victorieuse, connaît une grande fortune. Le cardinal Andrieu, archevêque de Bordeaux, va jusqu'à écrire au président du Conseil lui demandant de permettre à la France d'« arborer l'image $\mathrm{du}$ Cœur divin $»^{27}$. Une polémique s'ensuit, les anticléricaux rejetant l'idée de mettre les soldats sous la protection d'un insigne religieux, et par ailleurs certains théologiens réputés - tels que le cardinal Billot - étant irrités à l'idée de voir le signe du Sacré Cœur sur un drapeau national : pourquoi les Allemands ne feraient-ils de même pour s'affronter aux Français ? Les autorités républicaines hésiteront quant à l'attitude à avoir face à ce détournement de l'emblème de la République, sur lequel elles sont souvent très sourcilleuses.

\section{Consécration : honneur et outrages}

Plus que le choix d'un lieu sacré et que la vénération d'objets symboliques, la consécration est une pratique essentielle, base et conséquence, du vœu. Depuis le XVII siècle, déjà dans le vœu bérullien de servitude à Jésus et à Marie, ce don total et radical de soi apparaît comme une formulation volontaire et solennelle qui reprend la consécration opérée chez le chrétien par le baptême. Dans la spiritualité française du XVII ${ }^{\mathrm{e}}$ siècle, la consécration devient une forme normale de la dévotion à Marie: non seulement chez Saint Jean Eudes, Saint Louis-Marie Grignion de Montfort ou l'archidiacre d'Évreux qui consacre son archidiaconé par des formules d'« oblation » spécifiques, mais aussi chez Louis XIII qui offre son royaume à la Vierge ${ }^{28}$. Par la consécration corps, âme, biens de tout genre, tout est offert en «oblation», à la divinité, encore plus profondément que dans les vœux de religion.

31 Plus tard, la consécration au Sacré Cœur ira de pair avec la dévotion naissante - consécration privée, profession de foi du chrétien qui renouvelle les vœux du baptême. Au XVIII ${ }^{\mathrm{e}}$ siècle les consécrations collectives commencent à se propager: l'exemple le plus célèbre, peut-être parce que le premier, est «le vœu de Marseille » de 1722, inspiré par son archevêque, Mgr. de Belsunce, pour demander la protection divine contre la peste. Galliffet en parle déjà en 1733 :

[...] les Évêques et les Magistrats s'unirent pour consacrer au Cœur de Jésus-Christ, par des vœux publics, les Villes qu'ils gouvernaient: on s'engagea à la face des Autels, par les actes les plus solennels, à rendre chaque année à ce Cœur adorable des honneurs publics et à en faire la fête à perpétuité, avec des cérémonies qui devaient marquer à la postérité une reconnaissance éternelle ${ }^{29}$.

Pour lutter contre les fléaux d'autres villes et diocèses, Autun, Lyon, Aix, Arles, Toulon, imitent Marseille; Amiens, attaqué par le choléra en 1866, se confie aussi à la foi dans le Sacré Cœur.

L'acte de consécration, réponse collective aux désastres naturels, est d'autant plus courant lors de la guerre contre l'Allemagne: entre octobre 1870 et décembre 1871 quatorze diocèses ont été consacrés au Sacré Cœur $^{30}$. Mais ces actes de consécration concernent congrégations, paroisses ou diocèses, dans une dimension religieuse. Avec l'avènement d'un nouveau régime en France après 1871, il est question d'une consécration publique du pouvoir civil qui règne sur le pays, d'un acte officiel de 
l'autorité souveraine ${ }^{31}$. Dès lors les thuriféraires de la dévotion au Sacré Cœur ne cesseront d'insister sur cette consécration qui devra être - terme important - nationale.

C'est pourquoi la cérémonie de consécration de la France, lors du pèlerinage à Paray-leMonial de juin 1873, tout en n'étant pas officielle, n'en est pas moins inédite et, dans la perspective des organisateurs, le prélude d'un mouvement rénovateur. En 1889, on insiste pour expier les méfaits de la Révolution et ouvrir une nouvelle ère si le vœu demandé dans le message au roi deux siècles auparavant se réalise : mais la République laïque, déjà consolidée, se mobilise moins pour la consécration que pour fêter les fastes du Centenaire. On lance alors une « croisade " pour la consécration des familles qui seront appelées à constituer les éléments vitaux, les cellules organiques de la nation.

Lors d'une autre période troublée de l'histoire nationale, pendant la Grande Guerre, les consécrations des diocèses à tonalité patriotique se multiplient. L'épiscopat décide, à l'occasion de la fête du Sacré-Cœur en 1915 - le 11 juin - la consécration de la patrie; et dans les régiments, les manifestations de piété, les pratiques individuelles en esprit d'oblation et de réparation, ainsi que le port d'insignes religieux sont courantes au point de susciter des blâmes des autorités militaires. Le cardinal Amette écrit un texte consacrant les familles et les armées.

Conduisez-nous à la victoire [...], accordez-nous le triomphe [...], les nations alliées vous implorent ${ }^{32}$.

Après la catastrophe de 1940 il semble que l'épiscopat ait refusé une cérémonie de consécration présidée par Pétain lui-même. Mais le sens expiatoire et purificateur donné au vœu de Louis XIV reprend vigueur dans la lecture pétainiste de la défaite :

[...] la France [...], nation chrétienne et non « République laïque » ne retrouvera sa grandeur [...] que lorsque les Français, mettant un peu moins leur confiance dans les puissances humaines et un peu plus en Dieu, se serviront ostensiblement avec foi, du signe qui doit triompher de toutes les forces sataniques coalisées et que Notre Seigneur a indiqué lui-même en 1689 : son Divin Cœur ${ }^{33}$.

La teneur intégriste et anti-républicaine d'un tel discours place le rappel du message à Louis XIV dans la mouvance des monarchistes et des groupes les plus traditionalistes ${ }^{34}$.

\section{Gallia devota}

Le vœu collectif au Sacré Cœur est donc énoncé souvent dans un contexte catastrophiste, dont ceux qui s'engagent par le vœu essaient de triompher: que ce soit la maladie, la guerre ou l'invasion étrangère. L'apaisement des troubles, la victoire sur l'ennemi ou la résolution des problèmes posés à la collectivité apparaissent donc comme la condition pour accomplir la promesse engagée dans le vœu: depuis le XvII ${ }^{e}$ siècle ce vœu est matérialisé par le choix d'un lieu sacré, par le culte des images et par le port de signes distinctifs, enfin par un acte symbolique qui engage la collectivité s'il est accompli par celui qui a le pouvoir et la légitimité pour le faire.

Les monuments votifs et les temples expiatoires en honneur du Sacré Cœur se multiplient dans la seconde moitié $d u$ xix ${ }^{e}$ siècle: mettre l'accent sur Montmartre en tant que basilique du vœu national ne doit pas faire oublier qu'une grande partie des églises construites et des chapelles aménagées depuis un siècle se fait sous le signe du Sacré Cœur. De même, c'est parce que le drapeau représente par excellence le symbole national que l'on a insisté ici sur l'apposition du Sacré Cœur sur un tel objet. La consécration à la divinité, enfin, peut être personnelle, privée, aussi bien que collective ou officielle : ce 
caractère politique - concernant la vie de la cité - est ce qui nous intéresse dans la mesure où la consécration se fait au nom de la collectivité instituée, où c'est un acte qui réalise le vœu, du roi ou de la nation.

Le message de 1689 s'adresse au roi et, à travers lui - malgré lui, selon certains - à la «fille aînée de l'Église »; et le frontispice de la basilique à Montmartre résume toute l'histoire du vœu: «Sacratissimo Cordi Iesu Gallia pœenitens et devota ». Dans la littérature apologétique, plusieurs titres désignent la France pour qu'elle mène à bien sa consécration: elle est la première parmi les nations chrétiennes - depuis Clovis -, le berceau de celle qui transmet le message - Marguerite-Marie d'Alacoque -, mais aussi celle qui est coupable d'engendrer et de transmettre les péchés du monde moderne ${ }^{35}$. Le Sacré Cœur-dit-on-a des sollicitudes pour toutes les nations croyantes mais les chroniques de la dévotion, dans la perspective franco-centriste de la tradition de Parayle-Monial, attesterait une prédilection pour la France. Rappelons que Jeanne d'Arc est canonisée dans les années vingt de ce siècle, de même que les Français Jean Eudes, Thérèse de Lisieux et Marguerite-Marie d'Alacoque.

La pratique religieuse est donc vécue avec une sensibilité fortement nationaliste : un bon exemple en sont les missels de ce tournant de siècle. Même dans le recueillement de la messe et la pratique toute personnelle de la prière, les fidèles sont amenés à associer la divinité et la nation, dans un même élan de ferveur. Du Missel de la France aux pieds du Sacré Cœur, dont l'autorisation ecclésiastique date de 1905, au Missel de la France devant le Seigneur, imprimé en 1931, nombreux sont les missels où les images et les ornements servant de cadre aux prières et aux lectures sont une véritable leçon d'histoire et en reprennent les jalons les plus marquants après les révélations de 1867. Un autre de ces missels $^{36}$ déploie la consécration progressive de la nation - et sa constitution, en fin de compte -, depuis sainte Geneviève et Clovis.

La France a marché la première et s'apprête à renouveler ses gestes d'autrefois pour la gloire et l'amour du Sacré Cour; alors elle recueillera l'effet des magnifiques promesses qui lui ont été faites ${ }^{37}$.

\section{Les républiques du sacré cœur}

Le privilège de « recevoir » le message du Sacré Cœur et d'y « répondre »-comme dit la littérature de dévotion - est revendiqué par d'autres pays hispano-américains. Ainsi la Colombie se veut, depuis un siècle, comme « la République du Sacré-Cœur ».

41 En Colombie, dans la période de réaction anti-libérale, postérieure à 1886, qui voit la signature d'un concordat et une alliance de l'Église avec le parti conservateur, on constate une vague de cérémonies de consécration, au niveau municipal: Cecilia Henriquez observe que dans les procès-verbaux des conseils municipaux et des assemblées départementales il est expressément question d'actes publics en l'honneur du Sacré Cœur ${ }^{38}$. En 1902, c'est l'État lui-même qui s'engage par la consécration, dans un acte officiel du président Manuel Jose Marroquin qui place des fonds publics destinés à la construction d'une basilique nationale, en expiation des maux causés par le libéralisme pendant le siècle qui vient de finir et comme symbole d'une paix retrouvée. Le temple sera celui du «vœu national »; vœu qui veut mettre fin à une guerre civile, la «guerre des mille jours». Henriquez juge que c'est sa vocation de rempart civique et politiquement neutre, qui explique l'enracinement du symbole religieux dans la culture locale. En 1913, l'édification de l'église n'arrivant pas à son terme, le Sénat vote des 
subventions supplémentaires. Et à l'occasion du congrès eucharistique national, la même année, le président Carlos Restrepo ratifie un décret du Congrès qui dit :

[...] en solemne y perpetuo testimonio de la fe y de los sentimientos católicos del pueblo y a fin de impetrar los favores de lo alto para la paz definitiva y el sólido engradecimiento de la República, la Nación Colombiana por medio de sus Representantes rinde homenaje de adoración y reconocimiento a Jesús Redentor en el Augusto Misterio de la Eucaristia.

Considéré comme un symbole national, garant de la conciliation des partis, le Sacré Cœur n'en restera pas moins associé aux conservateurs qui l'utiliseront lors de campagnes de consécration des familles et des institutions, jusqu'aux années cinquante de ce siècle. Sur les ondes de la radio nationale et dans les publications du ministère de l'Éducation nationale, le jésuite Felix Restrepo, orateur très populaire, associe son pays à une nation idéale, «Cristilandia » : l'union de l'Église et de l'État est la base d'un nouvel ordre. 1952, cinquantenaire de la consécration, en voit le renouvellement : une cérémonie officielle et l'institution du vendredi du Sacré cœur comme fête nationale ${ }^{39}:$ les consécrations d'institutions et la participation des plus hautes autorités de l'État continue d'être d'usage tout le long de cette décennie. En 1955 encore, le général Gustavo Rojas Pinilla rend hommage à la figure du Sacré Cœur, comme un véritable symbole politique :

[...] En este dia destinado a honrar el misterio de vuestro amor hacia los hombres, como Presidente de Colombia y en nombre de su católico pueblo vengo a renovaros la consagración oficial de la República y a reconoceros señor y dueño de los individuos y de las familias, fuente primera de la autoridad y fin último al que deben ser dirigidas nuestras acciones y palabras [...]. El programa de paz, justicia y libertad brota de vuestro evangelio. Una patria grande, respetada y libre, simboliza una bandera con tres colores sin división ni mancha, es postulado que vive al amparo de vuestra cruz desde la cual vuestros brazos abiertos nos predican fratemidad y vuestro corazón herido nos enseña perdón y amor $[. . .]^{40}$.

La République du Sacré-Cœur - titre de la version équatorienne du Messager - est aussi un titre de gloire revendiqué par l'Équateur. En fait, ce pays, voisin de la Colombie, mériterait davantage l'appellation dans la mesure où il se dévoue officiellement au culte à une date bien antérieure et sert de modèle dans le monde entier. Comme Pie IX l'écrit à l'archévêque de Quito, José Ignacio Checa y Barba,

[...] completamente feliz debe llamarse [...] la Nación cuya autoridad civil está unida con tan estrecho lazo a la sagrada, que ambas no se dirigen sino a la consecución del bien común. Un ejemplo de esta felicidad y, por cierto, rarísimo en la actual perturbación de todas las cosas, tenemos a la vista en esa República ${ }^{41}$.

En effet, les périodes présidentielles de Gabriel Garcia Moreno, 1861-1865 et 1869-1875, se caractérisent par un essor religieux encouragé à partir du sommet de l'État. Ayant vécu en France pendant les années 1855 à 1857 et fréquenté les cercles saint-sulpiciens, García Moreno dirige, sous le sceau d'un catholicisme intégral, un régime autoritaire. Pendant ces années, la dévotion au Sacré Cœur en Équateur, déjà importante au XVIII siècle, reprend vigueur - comme ailleurs - avec le retour des jésuites en 1862. Parmi les pays de la région, l'Équateur est sans doute celui où le catholicisme est le plus influent et le seul en Amérique latine à montrer un équilibre entre la population et le clergé. Le concordat signé en 1863, l'emprise de l'Église sur l'enseignement prépare le terrain à la consécration officielle du pays en 1873, la même année que les pèlerinages à Paray-le-Monial et que celle de l'initiative des députés français : comment une initiative a-t-elle influencé l'autre ou s'agit-il d'une simple coïncidence? 
L'assassinat de García Moreno en 1875 d'une manière aussi théâtrale qu'incompréhensible - suivi de celui de l'archevêque Checa y Barba - suscite un émoi considérable dans l'univers catholique et fait de lui un « martyr du Sacré Cœur ».

Le Messager du Cœur de Jésus, et les récits hagiographiques qui circulent à profusion dans le monde catholique, nourrissent l'admiration pour l'expérience équatorienne, jugée comme un modèle. Voici la phrase finale de la biographie du rédemptoriste, Augustin Berthe (1882) ${ }^{42}$ :

[...] puisse la France, en arrêtant son regard sur ce nouveau peuple du Christ, se rappeler qu'elle aussi fut autrefois la nation très chrétienne et comprendre que, pour sortir de l'abîme où la Révolution l'a plongée, il lui faut un García Moreno!

Michel Lagrée suggère quelques éléments expliquant les raisons du mythe ${ }^{43}$ : il situe le président assassiné dans une lignée de martyrs, de messagers de la divinité comme le malheureux Louis XVI, dans la lecture qu'a voulu en faire la Restauration, qui sied parfaitement au dolorisme de la dévotion traditionnelle. Ensuite, l'Équateur, petit pays pauvre et lointain, est considéré comme le modèle de la nation chrétienne : la religion, le symbole religieux du siècle sert à construire un projet national, dans un continent nouveau où il s'agit de bâtir l'État, de créer une nation. Lagrée insiste sur une image de l'Amérique latine, qui persiste jusqu'à nos jours, comme terre d'utopie porteuse d'un nouveau souffle pour le catholicisme : la dévotion au Sacré Cœur, le rôle de ses symboles dans la vie de la cité, en sont des preuves éclatantes.

Marie-Danielle Demelas, pour sa part, insiste sur la fondation d'un « royaume » chrétien dans une des jeunes républiques américaines: dépassant l'organisation du système politique en monarchie, en empire ou en république, l'initiative équatorienne contribue à préparer d'une certaine manière le tournant donné par l'Église en France sous le pontificat de Léon XIII, le ralliement.

L'essentiel au fond est dans la formule de consécration de l'Équateur ou plutôt du peuple équatorien, au Sacré Cœur (la nuance a son importance) : «Voici Seigneur votre peuple ; toujours, Jésus, il vous reconnaîtra pour son Dieu... » ${ }^{44}$.

L'expérience de García Moreno dont Louis Veuillot disait qu'il était « le plus ancien des modernes ». montre aux catholiques français qu'un État clérical peut être républicain ou qu'un État républicain peut être clérical. Un de ses successeurs à la présidence de l'Équateur, Luis Cordero, poursuit en 1892 cette orientation :

Je n'ai jamais cru que le catholicisme fût opposé à la véritable liberté; de sorte qu'entre lui et la République, il ne peut exister le moindre antagonisme ${ }^{45}$.

L'État clérical se maintient après l'assassinat de García Moreno. En 1883 la construction d'un temple national aux frais de l'État ${ }^{46}$, mais aussi des particuliers, est décrétée par le gouvernement. Un congrès eucharistique en 1886, les noces d'or de Léon XIII l'année suivante, la consécration de la république à l'immaculé Cœur de Marie en 1892, les actes d'allégeance à la divinité et à son vicaire se succèdent, en particulier sous la présidence de Caamaño. L'arrivée des libéraux au pouvoir, à la fin du siècle, entraîne de la part du gouvernement une attitude plus laïque qu'anticléricale malgré les craintes des opposants et les reproches de l'épiscopat: la constitution de 1897 conserve le catholicisme comme religion officielle, mais le régime du président Leónidas Plaza introduit le mariage et le divorce, ainsi qu'une nouvelle loi sur les cultes. Par contraste avec la Colombie de l'époque, l'Équateur libéral du tournant du siècle perd ainsi son statut de nation privilégiée parmi les enfants du Sacré Cœur. 
51 Même si c'est en Colombie et en Équateur que la dévotion s'est le plus politisée, d'autres pays hispano-américains, à différents moments de leur histoire, ont également recours à la consécration. En voici quelques exemples, qui ne prétendent pas être exhaustifs. En 1925, devant le monument au Sacré Cœur qui domine Sucre, la capitale institutionnelle de la Bolivie, le président Bautista Saavedra prononce ces mots lors des cérémonies commémoratives du premier centenaire de l'Indépendance.

Yo, Bautista Saavedra, presidente constitucional de la república de Bolivia, consagro pública y oficialmente la república al Sagrado Corazón de Jesús, como afirmación de la fe del pueblo boliviano, el cual espera de El sus bendiciones para sus instituciones y el bienestar para sus ciudadanos ${ }^{47}$.

Pour célébrer le premier centenaire de l'Indépendance, le Costa-Rica est aussi consacré au Sacré Cœur, en présence du gouvernement tout entier ${ }^{48}$.

Peut-on en conclure que le recours à des pratiques et à des symboles religieux dans certains pays latino-américains contribue à la naissance et à la consolidation de l'entité nationale? L'Église contribue-t-elle à la diffusion des valeurs nationalistes et à la légitimation de l'État? La dévotion au Sacré Cœur, catholique dans son sens le plus étymologique, c'est-à-dire universelle, se transforme en nationalisme ${ }^{49}$.

\section{Le vœu universel}

54 En 1899, Léon XIII publie l'encyclique Annum sacrum, selon lui-même l'acte le plus important de son pontificat : il s'agit de préparer l'année sainte de 1900 et de commencer le nouveau siècle par un acte de consécration du "genre humain » au Sacré Cœur, aboutissement de tant de consécrations de tout ordre qui s'accélèrent dans le dernier tiers du XIX ${ }^{\mathrm{e}}$ siècle.

Des cérémonies ont lieu ici et là, aussi bien lors de la fête du Sacré-Cœur, en 1899, que pour le nouvel an qui ouvre le $\mathrm{xx}^{\mathrm{e}}$ siècle : des actes solennels, présidés par le pape, qui concernent l'humanité toute entière, croyants de toutes fois confondus et infidèles. La spiritualité de Paray-le-Monial est ainsi portée à l'échelle de "l'univers », au début d'un siècle qui verra la généralisation des échanges et des influences : la consécration de soi pour l'expiation des péchés des jansénistes et des protestants est étendue ainsi à tous les peuples. De sorte que cette consécration du «genre humain » dépasse le vœu, royal ou national et ne concerne plus les chefs d'État. C'est au pape en tant que «vicaire du souverain suprême " qu'il revient de prononcer cet acte de consécration pour ouvrir un nouveau siècle qui verra la transformation du Sacré Cœur en Christ-Roi. Les cérémonies ont lieu simultanément dans différents coins du globe pour faire écho à celle de Rome et elles sont réduites à un sens religieux. Tous les termes de la consécration de 1900 renouvelée par Pie X en 1906, remise à jour par Pie XI qui institue en 1925 la fête de Christ-Roi, relèvent du champ sémantique de la foi plus que de la vie politique :

[...] dans tous les diocèses, dans toutes les cathédrales, dans toutes les églises et chapelles de l'univers chrétien, le même acte solennel a réuni les âmes dans le même élan de piété filiale..$^{50}$

L'acte de consécration s'accompagne, une fois de plus, du vœu de construction d'un lieu de culte, d'un ex-voto qui matérialise la croyance dans l'espace, à l'échelle universelle. Mais où? Le choix se porte naturellement sur Rome : un temple qui puisse être considéré comme plus catholique que romain. Un projet revient en 1881 au célèbre prêtre italien Don Bosco; mais cette église, construite dans les nouveaux quartiers de la ville sainte 
près de la gare et des hôpitaux n'a jamais eu la dimension d'autres sanctuaires répondant à un vœu national.

Par ailleurs, dans l'entre-deux-guerres et de pair avec l'évolution de la figure du Sacré Cœur, il sera question d'ériger une basilique à Jérusalem, sur le Mont des Oliviers appelé aussi Mont des Nations et tenu pour la montagne apostolique par excellence, qui réunit la volonté d'expiation et la spiritualité victimale avec l'apostolat et le travail d'évangélisation des non-croyants. Le point de départ est toujours un vœu, prononcé au plus fort de la Grande Guerre chez les visitandines de Toulouse.

Le vœu a pour but d'obtenir du Sacré Cœur que toutes les Nations du monde entier

s'unissent dans la même foi pour établir le Règne universel de Dieu dans la paix ${ }^{51}$.

Annum sacrum et l'appel à la consécration du genre humain auraient été inspirées à Léon XIII par Sœur Marie du Divin Cœur, une religieuse, née Droste zu Vischering, recluse à Porto. Celle-ci, si l'on en croit son hagiographie ${ }^{52}$, aurait écrit au pape au début 1899 pour lui transmettre les messages reçus du Sacré Cœur et le convaincre de l'opportunité de la consécration. Sa démarche et sa spiritualité mystique rappellent Marguerite-Marie d'Alacoque. Très proche de la mort et encouragée aussi par son confesseur, Sœur Marie du Divin Cœur écrit.

On pourrait trouver étrange que Notre Seigneur demande cette consécration du monde entier et ne se contente pas de la consécration de l'église catholique. Mais son désir de régner, d'être aimé et glorifié et d'embraser tous les cœurs de son amour et de sa miséricorde est si ardent qu'il veut que Votre Sainteté lui offre les cœurs de tous ceux qui par le saint baptême lui appartiennent pour leur faciliter le retour à la vraie Église, et les cœurs de tous ceux qui n'ont pas encore reçu la vie spirituelle par le saint baptême, mais pour lesquels il a donné sa vie et son sang et qui sont appelés à être un jour les fils de la Sainte Église, pour hâter par ce moyen leur naissance spirituelle ${ }^{53}$.

Contrairement au roi, le pape reçoit le message divin. Ému par cette lettre, il décide de s'y soumettre. La décision prise en mars est communiquée en primeur aux évêques présents à Rome pour le $\mathrm{I}^{\mathrm{er}}$ concile provincial latino-américain. À l'aube $\mathrm{du} \mathrm{xx}^{\mathrm{e}}$ siècle la tradition du vœu au Sacré Cœur et la consécration qui lui fait suite prennent ainsi un nouvel élan, en renouant avec les éléments du récit primitif.

\section{Quelques remarques pour conclure}

De même que le vœu particulier, ce qu'on appelle les vœux de religion, spécifique à certains états religieux, participe d'un phénomène de conversion interne, qui s'ajoute à la foi commune et vient l'enrichir, la pratique du vœu collectif constitue une forme de conversion qui réaffirme et recompose un engagement chrétien préexistant. On a tenté de montrer que le vœu apparaît comme un lien ritualisé qui engage une communauté, et même qui la construit sous une forme idéale, que ce soit le royaume, la Nation ou l'univers.

61 L'accomplissement du vœu, l'acte de consécration rend sacrée une chose ou une personne, l'affecte d'un caractère qui la soustrait aux appréciations et aux usages communs; comme le roi était sacré à Reims, la nation ou la République s'ennoblissent d'une valeur incomparable, si l'invocation au Sacré Cœur lui apporte cette sorte de plusvalue religieuse. 

promesse à une autorité de tutelle, à qui il reconnaît une légitimité. La consécration, on l'a vu, ne peut être accomplie que par celui qui a l'autorité, politique ou morale. L'expression et le renouvellement du vœu sont ainsi une manière d'asseoir le pouvoir de cette autorité. Le vœu collectif, incontestablement promesse à la divinité, est aussi hommage à l'autorité dans la mesure où celle-ci prononce le vœu. On restaure la légitimité des Bourbons en associant le salut de la France au Sacré Cœur, comme plus tard, dans les pays hispano-américains, l'accomplissement du vœu national contribue à consolider les autorités de l'État. Les consécrations au Sacré Cœur sont alors « constitutives » de l'entité sacrée et non pas simplement « déclaratives ${ }^{54}$.

\section{Petit épilogue récent}

Toulon et Orange sont des municipalités récemment conquises par le Front National, formation d'extrême droite qui est loin d'exiger de ses militants des convictions chrétiennes. Pourtant Toulon et Orange ont été officiellement «consacrées » au Sacré Cœur par leurs maires respectifs, en octobre 1996 et en juin 1997, sans que les autorités ecclésiastiques prennent part aux cérémonies.

\section{NOTES}

1. Alain Boureau, "Pour une histoire comparée du vœu, Introduction », Cahiers du Centre de recherches historiques, $\mathrm{n}^{\circ} 16$, avril 1996, p. 7-10.

2. Marguerite-Marie d'Alacoque, Lettre IIC, 17 juin 1689, Vie et œuvres, vol. II, Paray-le-Monial, Paris, Poussielgue, 1867, p 199

3. Lettre CIV, août 1689, Ibid., p. 212.

4. Michel Christian, Une page religieuse de notre histoire nationale, Paris, Téqui, 1938, p. 110 ; René Laurentin, Le Vœu de Louis XIII. Passé ou avenir de la France, Paris, Ciil, 1988.

5. Si ce lien explicite entre la dévotion et la nation n'est pas nouveau, d'une manière certaine, il est forgé pendant ce $\mathrm{XVII}^{\mathrm{e}}$ siècle où la spiritualité fait une place moindre, dans les nouvelles congrégations fondées à cette époque, aux vœux de religion. Parlant des Oratoriens, Louis Cognet parle d'une théorie minimaliste des vœux, « Les vœux de religion dans la spiritualité française du $\mathrm{XVII}^{\mathrm{e}} "$, Cahiers eudistes de Notre Vie, ${ }^{\circ}$ 6, 1063.

6. Beaucoup d'éditions : la première en français, à Lyon, chez Pierre Valfray, 1733.

7. Messager du Sacré-Cœur de Jésus, vol. XII, 1867, p. 149.

8. Auguste Hamon, Le Message du Sacré Cœur à Louis XIV, à la France, Paris, Beauchesne, 1918.

9. J. Le Brun parle de "nombreuses déformations" concernant la vie de sainte MargueriteMarie, aussi bien au niveau de la piété privée qu'au niveau du message politique, Dictionnaire de Spiritualité, vol. X, p. 354.

10. Ibid.

11. Chanoine Cucherat, Les Saints Pèlerinages de Paray-le-Monial et de Verosvres en l'honneur du Cour de Jésus et de la Bienheureuse Marguerite-Marie, Paris, Palmé, 1873, p. 77.

12. Le Salut de la France, Toulouse, Manavit impr. du Roi, 1818, p. 9. 
13. Ibid.

14. Philippe Boutry, « Le Roi martyr », Revue de l'Église de France, LXXVI, 1990.

15. Hamon, Message..., p. 77. Dans son Histoire de la dévotion au Sacré Cour (vol V, 1939, p. 29), Hamon souligne que le décret de canonisation de Marguerite-Marie d'Alacoque en 1920 unit très intimement le vœu de Louis XVI et la demande de 1689; L'abbé Charles Marcault consacre un livre entier à répondre à la question: le message de 1689 a-t-il été réellement abandonné ? (Prieuré de Saint-Louans, Chinon, 1918).

16. Publié chez Mathias, en 4 pages, 1863.

17. Charles de Freycinet, La Guerre en province pendant le siège de Paris, cité par Raymond A. Jonas, «Monument as Ex-Voto, Monument as Historiography: The Basilica of Sacré-Cœur », French Historical Studies, vol. 18, n 2, 1993, p. 486, n. 12.

18. La France et le Cour de Jésus, Paris, Haton, Poitiers, Bonamy, 1884.

19. «Nous promettons [...] de contribuer selon nos moyens à l'érection à Paris d'une église consacrée au Sacré Cœur de Jésus", Vœu au Sacré Cœur pour obtenir la délivrance du Souverain Pontife et celle de la France, 2 p., Pau, Impr. E. Vignancour, 1871.

20. «Venite Adoremus », Bulletin de l'Euvre du vœu national, 9, 10 déc. 1884, p. 947, cité par Jonas, art. Cit., p. 491.

21. Michel Cinquin, «Paray-le-Monial ", in Philippe Boutry, Deux pèlerinages au XIXe siècle, Paris, Beauchesne, 1980, p. 228.

22. Cité par Letierce, Le Sacré Cour, ses apôtres et ses sanctuaires, Nancy, Le Chevallier, 1886, p. 447.

23. L'expression est de Cinquin, Ibid.

24. Hamon, Message..., p. 82.

25. Le 29 juin 1890, selon Hamon, Histoire..., vol. V, p. 321 ; R. du Bouays de La Bégassière, Le Drapeau national au Sacré Cour, ses origines, anc. Maison Douniol, Téqui, s. d., rend compte de la discussion à ce sujet, jusque en 1896.

26. Ibid., p. 83.

27. Cité par Jean-Marie Mayeur, Histoire du peuple chrétien, vol. II, Toulouse, Privat, 1979, p. 187 ; Jacques Fontana, Les Catholiques français, 1914-1918, Cerf, Paris, 1990, p. 234-239.

28. Joseph de Finance, "Consécration ", Dictionnaire de spiritualité, vol. II, p. 1579-1583. La Triple Couronne de la Bienheureuse Mère de Dieu, du P. François Poiré - première édition en 1632 - est considérée comme un "témoin irrécusable du progrès de la pratique de la consécration", contemporain du vœu de Louis XIII.

29. Galliffet, op. cit., p. 20.

30. Cinquin, op. cit., p. 181, n. 16 ; cependant la vague de consécrations diocésaines commence auparavant. En 1850, dix conciles provinciaux décrètent la consécration de cinquante diocèses. Mais tous les autres suivent à partir de 1870.

31. À cette époque il est question de «consécration nationale » dans d'autres pays aussi ; en Belgique en 1868, en Italie au début de la décennie suivante, en Irlande en 1873: «Algunas palabras sobre la consagración de naciones, diócesis e iglesias particulares al Sagrado Corazón ", El Mensajero, Mexico, vol. VII, 1890, p. 345.

32. La Semaine religieuse de Nice, 25 mai 1917, cité par Fontana, op. cit., p. 236.

33. Pierre Salgas, Le Message de 1689 du Sacré Cour à la France, Montsurs (Mayenne), édit. Resiac, 1982, (première édition en mai 1940), p. 3.

34. Outre le livre cité dans la note précédente, réimprimé avec des photos de Pétain en 1982, on peut citer, chez le même éditeur, Le Sacré-Cœur et la France, du marquis de la Franquerie. Selon ce dernier, Pétain accepte le principe de la consécration mais ajoute que c'est seulement le roi de France qui est qualifié pour la faire.

35. Une continuité très nette apparaît de Cucherat, op. cit., 1873, à Victor Alet, La France et le Sacré Cour, ou Letierce, op.cit., 1886, pour ne citer que quelques exemples, jusqu'à François Veuillot, La Dévotion française et la guerre, Bloud et Gay, 1916. 
36. Missel du Sacré-Cour, Dijon, Roux-Marchet et compagnie, 1906 [?].

37. Missel de la France aux pieds du Sacré-Cour, Limoges, Marc Barbon édit., 1909 [?], p. 17. Je tiens à exprimer mes remerciements à Aline, qui m'a indiqué l'existence de ce riche matériel.

38. Cecilia Henriquez, "El Sagrado Corazón, una cuestión politica o de religiosidad popular », communication au VI Congreso de antropologia en Colombie, manuscrit dactylographié, p. 2-3 ; cet auteur conclut «Es un simbolo de poder que no surge de abajo hacia arriba, no surge de las clases populares sino que se impone desde las instituciones que estan en manos de las clases altas del pais » ; Fernán González G., Partidos politicos y poder eclesiástico, Bogotá, Cinep, 1977.

39. Ibid., p. 9-10.

40. El Espectador, Bogotá, 17 juin 1955, cité par Henriquez, art. cit., p. 14. L'idée du drapeau du Sacré Cœur n'est envisagée qu'en tant que métaphore, dans les célébrations de la fête, en Colombie. À notre connaissance ce pays n'a pas vu l'apparition d'étendards qui associent les couleurs nationales à la figure religieuse, comme c'est le cas en France ou au Mexique.

41. La Voz del Clero, 10 de agosto, 1874, cité par Jose Felix Heredia SJ, Consagración de la República del Ecuador al Sagrado Corazón, Rasgos históricos, Quito, Ecuatoriana, 1935, p. 271.

42. Augustin Berthe, García Moreno, président de l'Équateur, vengeur et martyr du droit chrétien, Paris, Bertaux-Bray, 1888, p. 419.

43. "La Révolution et l'imaginaire catholique en France à la fin du XIX siècle », in Jean-Clément Martin, Religion et Révolution, Paris, Anthropos, 1994.

44. Marie-Danielle Demelas et Yves Saint-Geours, Jérusalem et Babylone. Politique et religion en Amérique du Sud : l'Équateur, XVIII'-XIX ${ }^{e}$ siècles, Recherche sur les civilisations, 1989, p. 155, p. 202.

45. Cité par Lagrée, art. cit., p. 209.

46. Berthe, op. cit., p. 406 ; Mensajero, Bilbao, nov. 1883.

47. Détails de la consécration, Mensajero, Quito, $1^{\mathrm{er}}$ oct. 1925.

48. Enrique Dussel, Historia general de la Iglesia en America latina, Mexico, Paulinas, vol. VI, 1985, p. 417. Un travail en cours tente de regrouper les informations éparpillées dans les ouvrages d'histoire religieuse et dans la littérature de dévotion, pour tenter une vision d'ensemble, dans une perspective comparatiste. Les consécrations existent dans presque tous les pays latinoaméricains. Au Pérou, avec le retour des jésuites dans les années 1880, les consécrations au SacréCœur se multiplient ; Jeffrey Klaiber, La Iglesia en el Perú, Lima, Pontificia Universidad Católica, p. 130 ; encore au Panamá, en 1959, le président Ernesto de la Guardia, suivi de 30000 citoyens, consacre la République.

49. «La politisation de la dévotion» est traitée comme l'un des aspects fondamentaux du catholicisme du tournant du siècle par Daniele Menozzi, qui ajoute «Si tratta di un terreno ancora mal esplorato dalla storiografia; ma alcuni sondaggi mostrano chiaramente l'ampia penetrazione di questa prospettiva nella pietà concretamente vissuta dai cattolici e poi anche nella liturgia ufficiale ", Storia del cristianesimo. L'Età contemporanea, Laterza, 1997, p. 159 ; Menozzi s'arrête sur le culte du Sacré-Cœur, manifestation particulièrement importante, selon lui, de cette tendance, p. 162, ss.

50. Hamon, Histoire..., vol. V, p. 181.

51. Jean-Baptiste Lemius (ancien supérieur de la basilique de Montmartre), Le Cour apostolique de Jésus et le vœu de l'univers catholique au Sacré-Cour, Toulouse, Privat, 1932, p. 17 ; il cite la lettre de soutien de Pie XI du 12 mars 1923 au projet de Jérusalem : « ne serait-ce donc pas pour répondre à un plan divin qu'en 1917 les Nations angoissées voulant obtenir du Cœur de Jésus la paix dans la justice et la charité, se sont tournées vers Jérusalem, vers le Mont des Nations, vers le Mont des Oliviers, d'où leur est venu le premier appel du Cœur apostolique?»; Georges de Noaillat, Le Règne social du \$, Tours, Mame, 1921.

52. Signée Louis Chasle, Paris, Beauchesne, 1905.

53. Ibid., p. 353 ; Émile Berghi, «Le cinquantenaire de la consécration au Sacré-Cœur ", Nouvelle revue théologique, juin 1949 ; cet auteur indique que l'idée d'une consécration de l'univers, mais à 
la Vierge, aurait germé déjà sous Pie IX, rattaché à la vague d'apparitions mariales. Pie XII, en 1942, rend hommage solennel au Cœur Immaculé de Marie, avec le même modèle du Sacré-Cœur. 54. Une consécration « déclarative " serait le renouvellement des promesses du baptême qui ne modifie en rien l'état du chrétien, mais le réactualise; un exemple de consécration «constitutive» serait en revanche l'expression des vœux de religion. Toutes les remarques proposées dans cette conclusion s'inspirent de l'article de Joseph de Finance « consécration ». 